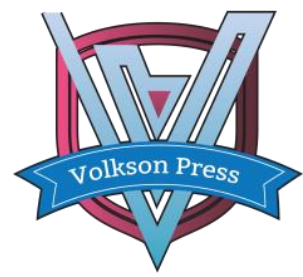

Contents List available at VOLKSON PRESS

Engineering \& Technology Innovations (ETI)

DOI : http://doi.org/10.26480/iceti.01.2017.06.10

\title{
DATA ACQUISITION SYSTEM BASED ON VIRTUAL INSTRUMENTS FOR PRE-STRESS CHARACTERISTICS OF EXPANDABLE BACKFILL MATERIALS AND COMPUTATIONAL SIMULATION
}

\author{
Qian Zhao-ming*t, Yuan Yan-bin*, Zhang Sa-sa*, Wang Yu-jie*, Ren Gao-feng* \\ (* School of Resources and Environmental Engineering, Wuhan University of Technology, Wuhan Hubei 430070, China; ${ }^{\dagger}$ Daye Nonferrous Metals Group \\ Holdings Co., Ltd., Huangshi Hubei 435005, China)
}

\section{ARTICLE DETAILS}

\section{Article History:}

Received 02 october 2017 Accepted 06 october 2017

Available online 11 october 2017

\section{Keywords:}

virtual instrument; data acquisition system; filling mining; roof-contact filling; pre-stress

\section{ABSTRACT}

The applying proportion of filling mining method is increasing considerably in mines as it meets the demands of building "two-oriented" society. However, due to the influence of various factors, the backfill materials fail to contact the roof of goaf completely, causing the backfill materials can't play its role fully. In the paper, the over burnt calcium oxide is injected into goaf as cementations materials together with the tailings. Those mixed backfill material will swell in a relatively short period of time and fill the goaf thoroughly. When the volume expansion is constrained by the boundry of the goaf, the backfill materials will exert stress on the surrounding rock. Firstly, stress data acquisition system based on virtual instruments was established when pre-stress measurement experiment was conducted, the goaf model was filled up with the expandable backfill materials (cement-sand ratio is 1:3 and concentration is $75 \%$ ), which exerted $0.76 \mathrm{MPa}$ and $0.42 \mathrm{MPa}$ pre-stress on the roof and bottom of the stope respectively after its volume expansion was limited and stopped. Moreover, the computational simulation was carried out for mutual verification and the results show that: keeping the initial filling rate 0.85 , the largest displacement and maximum stress in vertical direction of stope roof are $44.2 \mathrm{~mm}$ and 17.3MPa respectively when using the ordinary portland cement as backfill materials, however, the corresponding figures are only $4.6 \mathrm{~mm}$ and 12.1MPa when using the expandable backfill materials. In conclusion, the pre-stress measurement experiment facilitated by self-designed data acquisition system and computational simulation has proved that the expandable backfill materials are effective in controlling displacement and improving the stress distribution in surrounding rock.

\section{INTRODUCTION}

The applying proportion of filling mining method is increasing considerably in mines as it meets the demands of building "two-oriented" society. In China, the filling mining has gone through dry filling, water filling, cemented filling stage[ ${ }^{[1]}$.Currently, the most widely used filling method is cemented filling whose filling aggregate mainly is stone, gangue, and tailings and cementitious materials is often ordinary Portland cement. Due to the high cost of cement, mines that have their conditions replace cement with fly ash, red mud, slag, blast furnace slag and other cementitious materials partly or completely, and achieve better economic results ${ }^{[2]}$. But the filling body is affected by many factors, often failing to fully meet the roof ${ }^{[3-5]}$. There is usually clearance left from a few meters to several tens of centimeters between the roof and the backfill, resulting in the fail of filling body in playing its due role. Engineering and technical personnel improve the rate of filling body contacting the roof by improving the filling process and other means ${ }^{[-9-9]}$, but they can't fundamentally resolve the problem of filling body fully contacting the roof.

The main component of static expansion agent is overburnt calcium oxide. Calcium oxide reacts with water to produce calcium hydroxide and releases a lot of heat. When calcium hydroxide is doing its crystal development, its volume will expand. When the volume expansion is constrained by the boundary of the goaf, the backfill materials will exert stress on the surrounding rock. Blasting workers used this characteristics of over burnt calcium oxide to burst rock and concrete and other brittle material[10-11]. Now static expansion agent as a cementitious material is injected into goaf with tailings, forming expandable backfill. Expandable backfill body will expand in a certain period of time, filling the whole empty area, making backfill body touch surrounding rock very tightly, forming a mutual coupling integrity, making the best use of the advantage of backfill in the aspect of improving the surrounding rock stress distribution and controlling surrounding rock deformation. What's more, when the volume expansion of swelling backfill is constrained, the expandable backfill body can exert a certain amount of pressure on the surrounding country rock, changing from the original passive force into the active support of surrounding rock.

In order to figure out the effect of expandable backfill body in the aspect of improving the surrounding rock stress distribution and controlling surrounding rock deformation, firstly, we preliminarily chose the concentration range of expandable backfill mortar through segregation experiment ;Secondly, we got the expansion coefficient of swelling backfill in the free stage by measuring the volume value of expandable backfill mortar with different ratio in different periods in the free state. Thirdly, we collected the surrounding rock pressure when the expansion of expandable backfill mortar is limited by using pressure sensors and data acquisition system through similar experiment. Finally we compare and analyzed the effect of expandable backfill body and ordinary cemented backfill body in the aspect of improving the surrounding rock stress distribution and controlling surrounding rock deformation by using numerical simulation method.

\section{Segregation Experiment}

The purpose of the experiment is to preliminarily choose the concentration range of expandable backfill mortar. When the concentration of expandable backfill mortar is too low, the filling aggregate and the mortar will separate due to the lack of cohesion between the mortar and filling aggregate, not only reducing the mortar transmission capacity but also affecting the integral structure of backfill, which decrease the strength of the backfill greatly[12]. When the concentration of expandable backfill mortar is too high, the mortar transmission capacity is very weak, and can't be transported.

The ratio of static expansion agent and tailings ranged from 1:1 to $1: 6$ and 
the concentration of expandable backfill mortar varied from $50 \% \sim 80 \%$ in the experiment (Table 1). The backfill mortar with different ratio after being stirred sufficiently was left in a transparent container to stand for a period time to observe whether the layered segregation phenomenon will appear. The indoor temperature is $23{ }^{\circ} \mathrm{C}$, humidity is $70 \%$ when the expandable backfill mortar was made.

\begin{tabular}{ccccccc}
\hline Ratio & $1: 1$ & $1: 2$ & $1: 3$ & $1: 4$ & $1: 5$ & $1: 6$ \\
\hline Concentration & $60 \sim$ & $65 \sim$ & $70 \sim$ & $70 \sim$ & $70 \sim$ & $70 \sim$ \\
range(\%) & 80 & 80 & 80 & 80 & 80 & 80 \\
\hline
\end{tabular}

Table 1: The concentration range of expandable backfill mortar

Table 1 shows that with the ratio decreasing, the concentration range of expandable backfill mortar without segregation phenomenon is narrowing and the lowest concentration increases from $60 \%$ to $70 \%$ gradually, but the highest concentration does not change.

\section{Determination of coefficient of expansion of expandable backfill mortar in free stage}

The purpose of the experiment is to preliminarily know the expansibility of expandable backfill mortar. The backfill mortar with different ratio after being stirred sufficiently was left in a cylindrical plastic cup with a certain characteristic of expansion to stand for a period of time. The expanded volume of expandable backfill mortar was calculated by the diameter of cylindrical cup and the height of expandable backfill mortar after fully expanding using vernier caliper to measure in the plastic cup. The coefficient of expansion is the ratio of volume value after expandable backfill mortar fully expanding and initial volume value. The observation period was 30 days. The coefficient of expansion is shown in Figure.1.

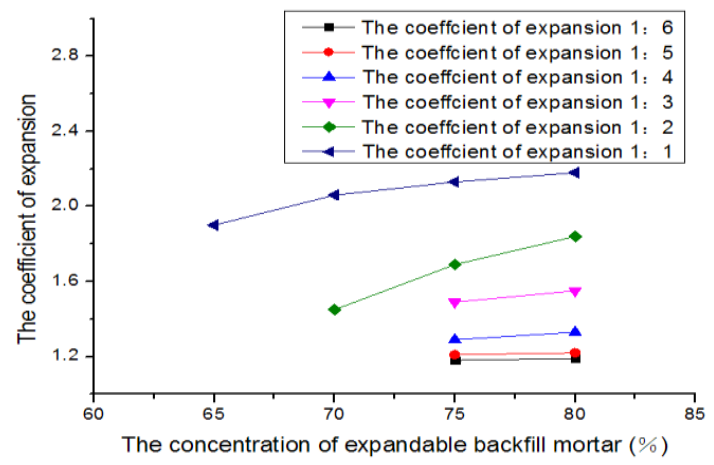

Fig.1 The expansion coefficient of expandable backfill mortar

As the Fig.1 shows, expandable backfill mortar has good expansibility. The value of expansion coefficient is closely related to the ratio of static expansion agent and tailings and the concentration of expandable backfill mortar. When the ratio of static expansion agent and tailings is higher, the concentration of expandable backfill mortar is higher and the expansion of expandable backfill mortar is better. When the ratio of expandable backfill mortar is 1:3 and the concentration of expandable backfill mortar is $75 \%$, the value of expansion coefficient can reach 1.49 . When the filling rate reaches 0.9 , the expandable backfill mortar with the ratio of 1:6 and the concentration of $75 \%$ after expanding can fill the whole empty area.

\section{Pre-stress measurement experiment of expandable backfill}

\subsection{Experiment purpose}

To measure pre-stress on the surrounding rock exerted by expandable backfill with the different ratio of static expansion agent and tailings when the volume expand is constrained.

\subsection{Experiment facilities}

A small scale model of goaf was made. The internal of goaf model is cube and the inner side is $10 \mathrm{~cm}$. The four micro pressure sensors were placed in the upper part, the lower part, the left and the right part in the internal model. After the backfill mortar production was completed, the mortar was injected into the goaf model. Then the model was placed on the tray of the hydraulic machine and the hydraulic machine limited displacement of roof by putting pressure on the roof. And the data of pressure sensors was collected by data acquisition system.

\subsection{Pressure measurement equipment}

The pressure measuring instrument is LY-350 micro pressure box, the measuring range is $5 \mathrm{MPa}$, Sensitive coefficient of Strain gauge is 2.0 .

\subsection{Data acquisition system}

The data acquisition system was developed based on Lab view software, which is a data acquisition and virtual instrument control software of a standard. Designed by graphical programming language, the acquisition system can achieve the real-time data communication between PC and sensors, accurately describes the stress status of the monitored site.

Specifically, on one hand, Virtual Instrument - VI is a pivotal applications which represent the virtual reality (Virtual Reality) in the instrumentation application and a modular hardware with high performance. On the other hand, Lab VIEW (Laboratory Virtual Instrument Engineering Workbench) has introduced a virtual instrument software development environment with a lot of built-in capabilities ${ }^{[13]}$. Easily, it is able to realize simulation data acquisition, instrument control, measurement analysis and data display functions. Furthermore, with user friendly interface, designers can take advantage of LabVIEW software to facilitate the realization of all the traditional functions of electronic measuring instruments. Wang Yawei[ ${ }^{[14]}$ designed a mine fans performance testing system based on Lab VIEW. Lv JunLin ${ }^{[15]}$ utilized the Lab VIEW virtual instrument to realize the real-time monitoring of gob for the sake of gob mining disaster analysis. The front panel of data acquisition system on PC terminal is displayed in Fig.2.

\section{Stress Data Acquisition System}

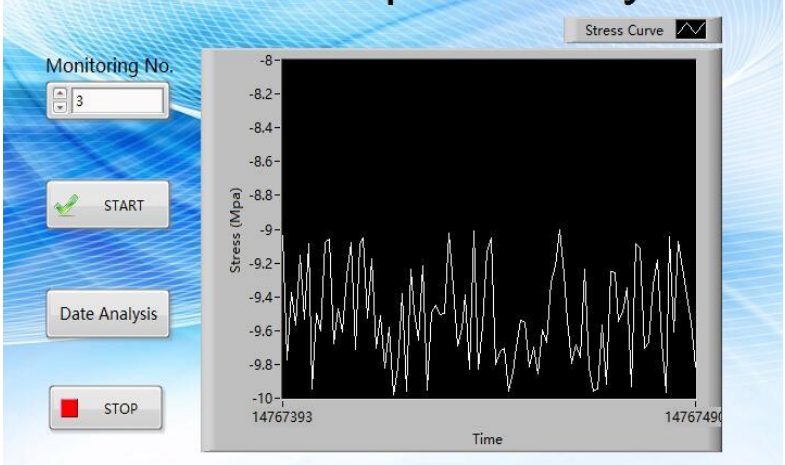

Fig.2 Front panel of data acquisition system

When the micro pressure box is pressured by the force, the inside resistance of the micro pressure box changes due to the deformation of resistance strain gauges. Measuring circuit outputs the change of resistance in the form of voltage signal. After collecting the voltage signal outputted by the micro pressure box, NI data acquisition card connect the database by DSN. The stored procedure of the database create a new table with the headers of serial number, date, channel coding in which the data will be put and saved. Block diagram is shown in Fig.3.

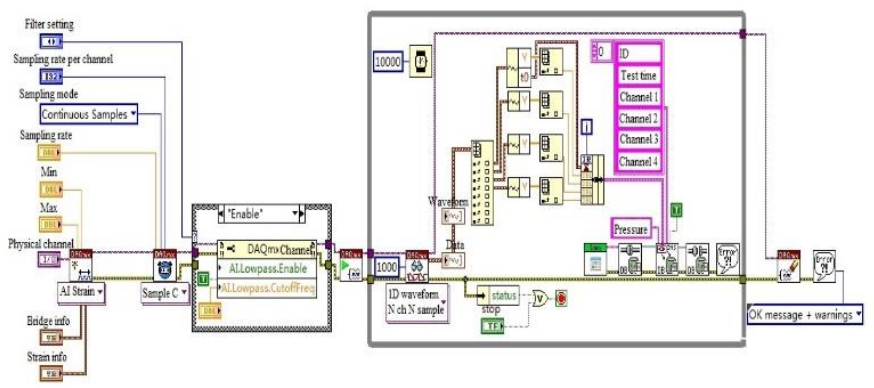

Fig.3 The program diagram of pre-stress data acquisition system

\subsection{Experimental procedure}

Based on segregation experiment and the result of determination of coefficient of expansion of expandable backfill mortar in free stage, the expandable backfill mortar with the concentration of $75 \%$ and the ratio of $1: 1 、 1: 3 、 1: 5$ respectively, was injected into the goaf model after being fully stirred. One of the height of the backfill mortar injected into the model with different ratio of static expansion agent and tailings was $10 \mathrm{~cm}$, the other was $8.5 \mathrm{~cm}$, that is one of the initial filling rate was 1 and the other 


\subsection{Simulation Content}

When the room became the empty area after excavation, the empty area was filled with original cemented backfill and expandable backfill respectively. When the filling rate was 0.85 , the height of the cemented backfill body was $6.8 \mathrm{~m}$ and the height of the expandable backfill body was $8 \mathrm{~m}$ after the volume expansion. When the filling rate was 1 , the heights were both $8 \mathrm{~m}$. It was studied that the improvement in stress distribution and the effect of controlling the displacement of the surrounding rock in the different filling rate of the two backfill body.

\subsection{Simulation results and analysis}

The geometric center was taken as the 0 point. And a vertical axis across the 0 point of the direction of the rooms in the plane of the roof was chosen. The range of the axis was outward $10 \mathrm{~m}$ from the width of the room, that was from $-20 \mathrm{~m}$ to $20 \mathrm{~m}$. It was studied that the variations of the displacement and stress in the vertical direction of the roof of the room in the vertical axis.

5.4.1 Simulation analysis of controlling surrounding rock displacement of expandable backfill material

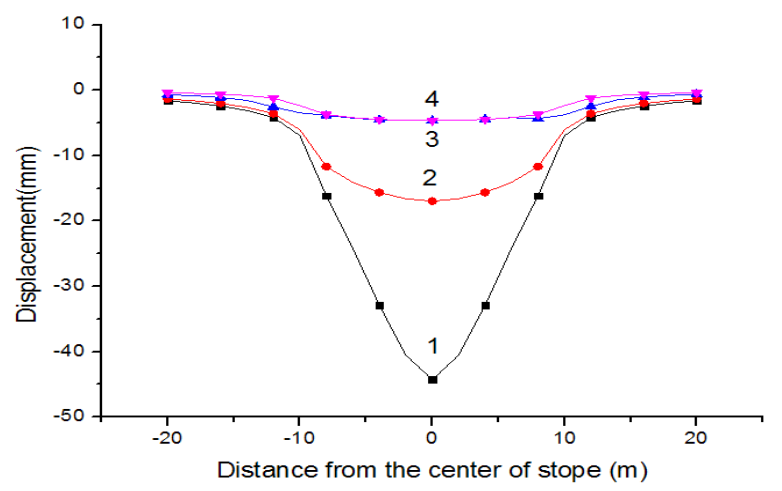

Fig.4 The displacement curve of stope roof from vertical direction

In the fig.5, the curve 1 shows the displacement in the vertical direction of the roof of the room with the filling rate of the ordinary backfill of 0.85 . The amount of subsidence across the center point in the vertical direction of the roof of the room was largest, $44.2 \mathrm{~mm}$ by the stress of the surrounding rock in the upper part because the roof lack in support due to the space between the roof and backfill. The amount of the subsidence gradually reduced from the center to sides and the final amount was 0 . The curve 2 shows he displacement in the vertical direction of the roof of the room with the filling rate of the ordinary backfill of 1 ., the amount of the subsidence in the vertical direction of the roof reduced considerably compared with curve 1 and the largest amount was $17.0 \mathrm{~mm}$ because the backfill connected to the roof and the roof was supported by the backfill. The curve 3 and curve 4 expressed the displacement in the vertical direction of the roof of the room with the filling rate of the expandable backfill of 0.85 and 1 respectively. The empty area was filled with the expandable backfill and the roof and backfill connected tightly, forming a whole due to the coupling effect so curve 3 and curve 4 were largely similar and the amount of subsidence was minimal. The filling body changed active support from passive force. The effect of the controlling of the subsidence of the roof was obvious.

5.4.2 Simulation analysis of improving surrounding rock stress distribution of expandable backfill material

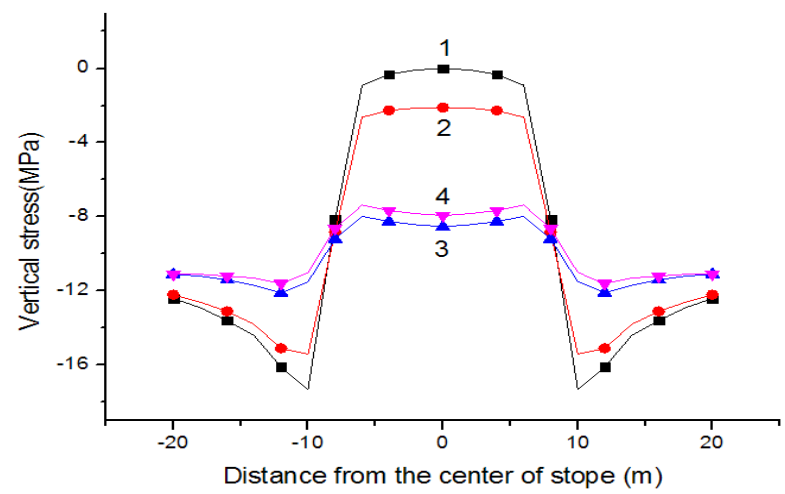

Fig. 6 The stress distribution curve of stope roof from vertical direction
In fig. 6 the Curve 1 expresses the stress distribution in the vertical direction of the roof of the room with the filling rate of the ordinary backfill of 0.85 . The stress in the center of roof transferred to the both sides. The center of the room did not bear pressure and the maximum stress in the vertical direction of the room appeared on the side of the room, the largest value was $17.3 \mathrm{MPa}$. The place of the maximum stress of the room would form the stress concentrated zone causing shear failure of the room. Curve 2 expressed the stress distribution in the vertical direction of the roof of the room with the filling rate of 1 of the ordinary backfill. The backfill played the role of transferring the stress. The largest value of the stress in the vertical direction of the roof of the room became smaller and the largest value was $15.4 \mathrm{MPa}$, appearing still on the side of the room. The Curve 3 and Curve 4 express the stress distribution in the vertical direction of the roof of the room with the filling rate of expandable backfill body of 0.85 and 1 respectively. At this time, The largest value of the stress in the vertical direction of the roof of the room reduced greatly. The largest value was $12.1 \mathrm{MPa}$ with the filling rate of 0.85 and the largest value was $11.6 \mathrm{MPa}$ with the filling rate of 1 . When the ordinary cemented material was used to fill the empty area, the change of stress gradient was larger. When the expandable backfill mortar was used to fill the empty area, the change of stress gradient was gentler. It's obvious that when the expandable backfill mortar is used to fill the empty area, the mortar can play a fully role in improving the stress distribution of the roof, strengthening the stability of the roof.

\section{Conclusion}

(1) A stress data acquisition system based on virtual instrument was designed utilizing graphical programming language, which can accurately and dynamically collect the stress status of monitoring spots. At the same time, computational simulation was carried out for mutual authentication for the pre-stress characteristics of the expansible backfill material.

(2) The expandable backfill mortar has excellent expansibility and the volume can expand in a short time. The value of the expansion coefficient is closely related with concentration and the ratio of the static expansion agent and tailings. The pre-stress that the expandable backfill mortar produces is closely related with the amount of the cementitious materials and they have a positive correlation when the expansion volume is limited.

(3) The expandable backfill mortar can solve the roof-contacted filling problem fundamentally. The expandable backfill mortar injected into the goaf with filling rate of 0.9 , the concentration of $75 \%$ and the ratio of the static expansion agent and tailings of 1:6 can fully fill the empty area after volume expansion.

(4) After connecting the roof, the expandable backfill body can fully play its role in controlling the displacement of the room and improving the stress distribution of the surrounding rock, strengthening the stability, ensuring safety in production. Mine can adjust the filling rate and the concentration and the ration of the static expansion agent and tailings to balance the safety in production and cost of filling to achieve the best balance point.

\section{Acknowledgement}

This paper is supported by self-determined and nnovative research funds of WHUT (Project No.: 2013-YB-028) and the Fundamental Research Funds for the Central Universities (Project No.: 2014-VII-023 and 2014IV-140).

\section{Reference}

[1] Xia Chang-nian, Xun Xie-sen. "The Application and developing trend of filled slopes method and filling technology"[J], China Mine Engineering, 43(1), pp. 61-64, (2013).

[2] Zhao Chuan-qing, Hu Nai-zhen. "The Development and Application of Cementitous Material of Filling"[J], Gold, 29(1), pp. 25-29, (2008).

[3] Zhou Xu, Yang Lu-hai, Bai Chao-xuan, et al. "Technical Improvement of Tight-filling of Cemented Filling" [J], China Mine Engineering, 41(4), pp. 46, (2012).

[4] Feng Sheng-li, Wang Ling-hui. "Study on Roof-contacted Filling Technology in Stope and Goaf'[J], China Mine Engineering, 40(4), pp. 1315, (2011).

[5] Zeng Zhao-kai, Zhang Yi-ping, "Shui-rui. Discussion on Control Measures for Raising the Rate of Supporting Pit Roof"[J], Modern Mining, (01), pp. 96-97, (2010). 
[6] Lu Yang-ze, Li Li-jun, Jiang Ren-yi. "Discussion on Raising the Rate of Supporting Pit Roof'[J], Nonferrous Metals(Mining Section), 61(3), pp. 6-8, (2009).

[7] Wang Shu-hai, Li Qi-yue, Zhao Guo-yan. "A Research on Technical Measures for Raising the Rate of Supporting Pit Roof"[]], Mining and Metallurgical Engineering, 31(1), pp. 13-15, (2011).

[8] Sun Yong. "Several Effective Action for Raising the Rate of Supporting Pit Roof'[J]. Modern Mining, (8), pp. 100-101, (2012).

[9] Jiang Ning, Deng Dai-qiang, Yao zhong-liang. "New Roof-Contacted Filling Technics in Cao Lou Iron Mine"[J]. Mining Research and Development, 30(3), pp. 18-19, (2010).

[10] Xiao Li-qun. "Excavation Blasting of Tai Shan Nuclear Power Plant Sea Reservoir and Drainage Tank"[J]. Blasting, 30(1), pp. 63-65, (2013).

[11] Wang Zhi-shen, Wang Hai-liang. "Application of Non-explosive Demolition Method of Excavation Project in Hard Rock Mine"[]], Blasting, 30(3), pp. 58-61, (2013)

[12] LI Wei, Zhou Xu, Liao Mei-quan. "Analysis and Control on the Segregation of Filling Material in High Concentration"[]], World Nonferrous Metals, (04), pp. 74-75, (2011).
[13] Chen Xi-hui. "LabVIEW 8.20 Master program design from scratch"[M]. Beijing, Tsinghua University Press, pp. 2-15, (2007).

[14] Wang Ya-wei, Gu Li-chen, "Long. Design of Performance Testing System for Mine Fan based on LabVIEW"[J], Mining and Processing Equipment, (03), pp. 36-38, (2007).

[15] Lv Jun-lin, Ren Gao-feng, Wang Yu-jie, et al. "GoafWireless Monitoring System Based on Technique of Virtual Instrument"[J], Metal Mine, (07), pp. 133-135, (2012).

[16] Song Hua. "Study on Underground Pressure Distribution Law and Control of Safety Pillars Mining under Buildings" [D]. Wuhan University of Technology, 2013.

[17] Wang Jie, Zheng Huai-chang, Cheng Xiao-ping. "The Mechanics Effct Analysis of Cemented Filling Body of Filling Mining Method"[J], Nonferrous Metals Engineering, 56(3), pp. 109-111, (2004).

[18] Lian Xiao-lin, Feng Guang-ming, Han Xiao-dong, et al. "Numerical Simulation of Open Stowing with Super-high-water-content Material by FLAC3D”[J], Coal Mining Technology, 16(1), pp. 4-7, (2011). 